\title{
Simulation of Vessel Motion Control by Anti-Rolling Tank
}

\author{
Kyung Sung Kim $^{*}$ and Byung-Hyuk Lee $\mathbb{1}^{* *}$ \\ *Ocean Development SystemSchool of Naval Architecture and Ocean Engineering, Busan, Korea \\ ${ }^{* *}$ Hyundai Heavy Industry Co. Ltd., Ulsan, Korea \\ 능동형 횡동요 저감 장치를 이용한 선박운동제어 시뮬레이션 \\ 김경성* 이병혁(* \\ "동명대학교 조선해양공학부 \\ "현대중공업(주)
}

KEY WORDS: Active anti-rolling tank 능동형 횡동요 저감 장치, Vessel motion with sloshing 슬로싱 효과, Moving particle semi-implicit 이동입자법

\begin{abstract}
The effects of an anti-rolling tank (ART) on vessel motions were numerically investigated. The potential-based BEM vessel motion simulation program and particle-based computational fluid dynamics program were dynamically coupled and used to perform a simulation of vessel motions with ART. From the time domain simulation results, the response amplitude operators for sway and roll motions were obtained and compared with the corresponding experimental and numerical results. Because the main purpose of ART was only to reduce roll motions, it was important to show that the natural properties of a floating vessel were not changed by the effects of ART. Various ART filling ratios and several ART positions were considered. In conclusion, ART only reduced the roll motion regardless of its filling ratio and position.
\end{abstract}

\section{1. 서 론}

지난 수십 년 동안 다양한 화물의 적재 용량을 증가시키기 위 해 선박의 크기는 지속적으로 증가해 왔다. 특히 적재 화물이 유체인 경우 선박의 고유주기가 바뀌거나 복수개의 고유주기를 가지기도 한다(Lee and Kim, 2010; Kim et al. 2011). 이로 인해 부유체 설계 시 환경조건에 대한 영향을 재평가해야 한다. 따라 서 이러한 문제를 해결하기 위해 부유체의 고유 특성은 변화시 키지 않으면서 가장 취약한 횡동요 운동을 적절히 제어할 수 있는 방안들이 제안되어 왔다.

빌지킬은 저(선저)에 기다란 판 형태의 부가구조물로 형상 저 항과 점성 저항을 증가시켜 선박의 횡동요를 저감하는 대표적 인 방법이다. U-tube 또는 Horizon-tube는 화물창 주변 혹은 $\operatorname{Deck}$ (갑판) 상부에 액체가 저장된 Tube를 탑재하여 선박의 횡 동요를 저감하는 Passive anti-rolling tank(PART)로서 Tube 내부 유동의 주기는 선박의 횡동요 주가와 Anti-phase이어야 한다. 이 러한 다양한 횡동요 저감 방식들 중 최근 능동형 횡동요 저감 장치(Active anti-rolling tank, AART)가 제안되고 있다. Marzouk and Nayfeh(2009)에서 제안한 AART는 기존의 U-tube 형태에서 중앙에 펌프를 이용하여 내부 유동을 능동적으로 관리하여 내 부 유동으로 인해 복원력을 증가시킬 수 있도록 고안된 장치이 다. 이러한 AART는 기존의 수동(Passive) 형태의 ART에 비해 다양한 방향에서 입사되는 파에 대해 대처할 수 있다는 장점이 있으나 탑재비용 및 유지관리 비용이 높다는 단점이 있다.

Cho et al.(2017)은 탱크 내부에 공극이 있는 격벽을 설치하여 슬로싱 저감에 미치는 영향을 정량적으로 평가하였다. Cho et al.(2017)에 의하면 격벽에 의한 탱크 내부 유동의 변화는 슬로 싱 효과 및 위상의 변화가 발생할 수 있음을 알 수 있다. Kim et al.(2016)에서는 ART를 탑재한 선박의 운동에 대해 해석하였으 며, 이는 선박에 장착된 $\mathrm{ART}$ 에 의해 선박의 운동 특성이 변화 함을 알 수 있다. Kim et al.(2018)에서는 실험적 방법을 통해 격 벽을 이용한 슬로싱 저감 장치의 효과에 대한 연구를 수행하였 다. 선행연구를 통해 ART의 정량적 평가를 통한 적합한 형태의 ART 탑재는 매우 중요하며, 이를 위해서는 내부유동해석과 내 부유동을 고려한 선박 운동에 대한 연구가 필요하다.

본 연구에서는 ART 내부 유동을 시뮬레이션하기 위해 입자

Received 9 May 2018, revised 2 December 2018, accepted 13 December 2018

Corresponding author Byung-Hyuk Lee: +82-52-202-2114, blue7892@gmail.com ORCID: http://orcid.org/0000-0001-7514-8235

(c) 2018, The Korean Society of Ocean Engineers

This is an open access article distributed under the terms of the creative commons attribution non-commercial license (http://creativecommons.org/licenses/by-nc/3.0) which permits unrestricted non-commercial use, distribution, and reproduction in any medium, provided the original work is properly cited. 
법을 사용하였다. 대표적인 입자법으로는 $\mathrm{SPH}(\mathrm{Smoothed}$ particle hydrodynamic)(Monaghan, 1994)와 MPS(Moving particle semi-implicit) (Koshizuka and Oka, 1996)법이 있으며, iSPH(Incompressible SPH) (Xu et al., 2009)법이 MPS법과 같은 방식의 압력 해법을 사용하 면서 두 방법의 차이가 많이 줄어들었다. 본 연구에서는 압력 진동제어 능력이 더 우수하다고 판단되는 MPS법을 사용하였다. MPS법은 Koshizuka and Oka(1996)가 처음 제안되었으며, 이 후 Tanaka and Masunaga(2010)가 포아송방정식의 소스항을 입자 속 도의 발산으로 정의하면서 압력의 안정화를 시도하였다. 이 방 식은 Lee et al.(2011)이 완화계수의 물리적 접근을 통해 더욱 안 정화되었다. 또한 Nomura et al.(2001)에서는 표면장력을 고려한 방식을 제안하였으며, 이는 Kim et al.(2014a)에서 법선 벡터의 정확도를 높이는 연구를 수행하였다.

선체 운동 해석에 관한 연구는 Yang and Kim(2011)이 Boundary element method(BEM)법을 사용하여 허리케인과 같은 극한 환경에 서의 Tension leg platform(TLP)의 거동에 관한 연구를 수행하였으 며, Lee et al.(2010)은 이를 확장하여 내부 유동에 따른 부유체의 운동 모사에 관한 연구를 수행하였다. Kim et al.(2014)은 Lee and $\operatorname{Kim}(2010)$ 과 동일한 문제에 대해 내부 유동을 입자법으로 해석하 는 방식에 대한 연구를 수행하였다.

본 연구에서는 Kim et al.(2011)이 수행한 연구를 기초로 하여 $\mathrm{ART}$ 의 유무가 부유체 운동에 미치는 영향뿐만 아니라 ART의 설치 위치 및 탱크 내부 적재율에 따른 영향을 평가하였다.

\section{2. 수치해석기법}

\section{1 부유체 운동 시뮬레이션}

부유체 운동의 시간영역 시뮬레이션을 위해 패널을 이용한 3 차원 산란 및 방사 프로그램으로부터 유체력 계수를 확보하여 야 한다. 유체력 계수 확보를 위한 시뮬레이션 기법의 자세한 내용은 Lee(1991)에서 찾을 수 있다. 패널기반 3차원 산란 및 방 사 프로그램으로부터 구해진 유체력 계수는 주파수영역에서의 값을 가지므로 이를 식 (1)에 나타난 Volterra expansion을 포함 한 중첩 적분 기법을 이용하여 변환하여 시간영역 시뮬레이션 프로그램에 입력값으로 사용하도록 한다.

$$
F_{R}=-M_{a}(\infty) \ddot{\zeta}-\int_{0}^{\infty} R(t-\tau) \dot{\zeta}(\tau) d \tau
$$

여기서 $M_{a}(\infty)$ 은 무한대 주파수에서의 부가질량, $F_{R}$ 은 방사에 의한 외력, $\zeta$ 는 부유체의 변위, $\dot{\zeta}$ 는 시간 미분, $t$ 는 시간, $\tau$ 는 참 조 시간, $R(t)$ 는 시간 $t$ 에서의 지연 함수이며, 중첩 적분에서 구 할 수 있는 값은 입사파로부터 부유체에 작용하는 파력이다. 앞 서 언급한 바와 같이 부가 질량을 포함한 유체력 계수는 먼저 주파수영역에서 구해진다. 따라서 식 (1)에서의 무한대 주파수 에서의 부가질량을 구하기 위해서 다음의 식을 이용한다.

$$
M_{a}(\infty)=M_{a}(\omega)+\int_{0}^{\infty} R(\omega) \frac{\sin (\omega t)}{\omega} d t
$$

여기서 지연함수 $R(t)$ 는 시간 기억 효과를 위해 사용되었다. 이
지연함수는 다음의 식으로 표현할 수 있다.

$$
R(t)=\frac{2}{\pi} \int_{0}^{\infty} C(\omega) \cos (\omega t) d \omega
$$

여기서 $C(\omega)$ 는 방사 감쇠 계수이다. 부유체 운동 계산에서 내부 유체 저장소의 충격력 및 관성력을 고려하기 위해서는 운동방 정식에 유체력을 고려하는 것이 일반적이다.

$$
\begin{aligned}
{\left[M+M_{a}(\omega)\right] \ddot{\zeta}+\int_{-\infty}^{t} R(t-\tau) \dot{\zeta}(\tau) d \tau } & +K \zeta=F(t) \\
& =F_{\text {ext }}(t)+F_{\text {sloshing }}(t)
\end{aligned}
$$

여기서 $M$ 은 부유체의 질량, $K$ 는 외부강성계수, $F(t)$ 는 외력이 며 외력은 파력과 부유체의 점성 감쇠력을 고려한 $F_{e x t}(t)$ 와 내 부 유체력을 고려한 $F_{\text {sloshing }}(t)$ 로 구성된다.

\subsection{Moving Particle Semi-implicit 법}

$\mathrm{ART}$ 의 내부에 작용하는 유체력을 계산하기 본 연구에서 사 용된 방법은 MPS이다. MPS법의 지배방정식은 연속방정식과 Navier-stokes 방정식으로 아래 식과 같다.

$$
\frac{D \rho}{D t}=0
$$

$$
\rho \frac{\overrightarrow{D u}}{D t}=-\nabla P+\mu \nabla^{2} \vec{u}+\vec{F}
$$

여기서 $\rho$ 는 유체의 밀도, $P$ 는 압력, $\mu$ 는 점성계수, $\vec{u}$ 는 입자의 속도, $\vec{F}$ 는 중력가속도를 포함한 외력에 의한 가속도이다. MPS 법은 완전 라그란지안법을 따르고 있기 때문에 지배방정식의 각 항은 입자상호작용 모델인 식 (7)으로 치환되어야 하며 이에 대한 자세한 설명은 Lee et al.(2011)에서 찾을 수 있다.

$$
\begin{gathered}
\text { Gradient Model } \quad \nabla \phi=\frac{d}{n^{0}} \sum_{j \neq i}\left[\frac{\phi_{j}-\phi_{i}}{\overrightarrow{r_{j}}-\overrightarrow{r_{i}}}\left(\overrightarrow{r_{j}}-\overrightarrow{r_{i}}\right) w\left(\left|\vec{r}_{j}-\vec{r}_{i}\right|\right)\right] \\
\text { Divergence Model } \nabla \cdot \phi=\frac{d}{n^{0}} \sum_{j \neq i}\left[\frac{\left(\phi_{j}-\phi_{i}\right) \cdot\left(\overrightarrow{r_{j}}-\vec{r}_{i}\right)}{\overrightarrow{r_{j}}-\vec{r}_{i}} w\left(\left|\overrightarrow{r_{j}}-\overrightarrow{r_{i}}\right|\right)\right] \\
\text { Laplacian Model } \\
\nabla^{2} \phi=\frac{2 d}{\lambda n^{0}} \sum_{j \neq i}\left[\left(\phi_{j}-\phi_{i}\right) w\left(\left|\overrightarrow{r_{j}}-\vec{r}_{i}\right|\right)\right]
\end{gathered}
$$

여기서 Laplacian 모델에 사용된 $\lambda$ 는 분산이 해석해와 동일하도 록 도입된 계수이다.

$$
\lambda=\frac{\sum_{j \neq i}\left|\overrightarrow{r_{j}}-\overrightarrow{r_{i}}\right|^{2} w\left(\left|\overrightarrow{r_{j}}-\overrightarrow{r_{i}}\right|\right)}{\sum_{j \neq i} w\left(\left|\overrightarrow{r_{j}}-\overrightarrow{r_{i}}\right|\right)}
$$

MPS법은 연속유체를 이산화된 입자로 모사하고 입자 하나하 나가 물리량을 가지고 이동하기 때문에 연속체 가정을 만족시 키지 못할 가능성이 있다. 따라서 이를 극복하기 위한 방법으로 가중치 함수를 도입하였다. 가중치 함수는 식 (7)에 있는 입자 
상호작용 모델의 기초가 된다. 가중치 함수는 주변입자가 중심 입자에 미치는 영향을 정량화 한 것으로 거리에 대한 함수이다 본 연구에 사용된 가중치 함수는 다음과 같다.

$$
w\left(\left|r_{i j}\right|\right)=\left\{\begin{array}{cc}
\left(1-\frac{\left|r_{i j}\right|}{r_{e}}\right)^{3}\left(1+\frac{\left|r_{i j}\right|}{r_{e}}\right)^{3} & \left(0 \leqq\left|r_{i j}\right|<r_{e}\right) \\
0 & \left(r_{e}<\left|r_{i j}\right|\right)
\end{array}\right.
$$

여기서 $r_{i j}$ 는 $\left(r_{j}-r_{i}\right)$ 이며, $r_{i}$ 는 $i$ 번째 입자의 위치벡터이다. $r_{e}$ 는 입자간 상호작용의 유효반경으로 본 연구에서는 $2.1 \times l_{o}$ 를 사용하였다. 여기에서 $l_{o}$ 는 초기 입자 배치 상태에서 입자가 평 균 거리이다. 식 (8)에서 보이는 것과 같이 만일 입자간 거리가 유효반경 $r_{e}$ 보다 클 경우 입자간 상호작용의 크기는 0 이다. 본 연구에서는 Lee et al.(2011)(PNU-MPS)에서 제시한 가변 시간간 격을 사용하여 입자가 벽면을 통과하는 문제를 해결하였다.

\section{3. 시뮬레이션 결과 및 논의}

탱크 내부 유동이 선체 운동에 미치는 영향을 Kim et al. (2014b)에서 알 수 있듯이 내부 유체가 없는 상태에서의 횡동요 운동의 고유주기는 약 $0.45 \mathrm{rad} / \mathrm{s}$ 이다. 그러나 Fig. 1 에서의 다른 적재량의 경우 내부 적재 유체 화물에 의해 고유주기의 극점 주기가 바뀌고 2 개로 나뉘는 현상이 발생함을 보였다. 이는 부 유체 운동의 고유 특성이 변화하는 것으로 초기 설계 시 복수

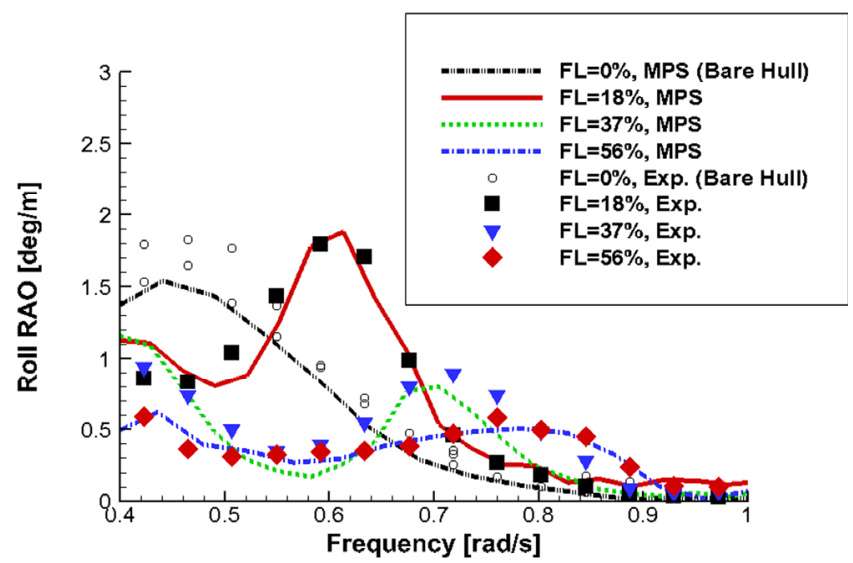

Fig. 1 Example of roll RAO of FPSO with two inner liquid tank for various inner tank ratio (Kim et al. 2014b)

Table 1 Characteristics of floating vessel and anti-rolling tank

\begin{tabular}{ccc}
\hline \hline Description & Floating vessel & $\begin{array}{c}\text { Inner sloshing tanks } \\
\text { (AFT / FWD) }\end{array}$ \\
\hline Length [m] & 285 & $27 /$ \\
Breadth [m] & 63 & $40 /$ \\
Draft (Height) [m] & 13 & $7 /$ \\
x-Position [m] & 0 & \\
y-position [m] & 0 & $0 / 0$ \\
z-Position [m] & 0 & $3 / 3$ \\
\hline
\end{tabular}

Table 2 Environmental Conditions

\begin{tabular}{ccc}
\hline \hline Wind & N/A \\
\hline Current & N/A \\
\hline \multirow{3}{*}{ Wave } & Significant height & 90 Degree (beam) \\
& Peak period & $5.0 \mathrm{~m}$ \\
& $\gamma$ of JONSWAP spectrum & 3.3 \\
\hline $\begin{array}{c}\text { Filling level of } \\
\text { inner tanks }\end{array}$ & \\
\hline
\end{tabular}

개의 고유주기를 고려해야하며 이는 내부유동의 영향에 의한 변화임을 알 수 있다. Kim et al.(2014a)에서 사용한 Box-barge 형태의 FPSO(Floating production storage and offloading)와 환경 변수는 Table 1과 Table 2에 나타나 있다.

Kim et al.(2014b)에서 연구된 내용을 바탕으로 내부 유동이 부유체 운동에 영향을 끼침을 알 수 있었다. 본 연구에서는 이 러한 현상을 재해석하여 내부 유동을 이용하여 부유체 운동 특 성을 변화시키는 즉 운동을 저감시키기 위한 연구를 수행하였 다. 연구 수행을 위한 부유체는 Kim et al.(2014b)에서 사용된 MARIN(Maritime Research Institute Netherlands)의 Box-barge FPSO를 사용하였으며(Fig. 2(a)) 선체에 Anti-rolling $\operatorname{tank(ART)}$ 를 탑재하고 있다. 탑재된 ART는 Fig. 2(b)에 나타난 것과 같이 사 각 형태로 내부에 닫히지 않은 격벽을 포함하며 부유체 운동의 위상(Phase angle)을 변화시키는 역할을 한다. 격벽의 길이는 $\mathrm{ART}$ 길이 방향의 $25 \%$ 를 사용하고 있으며 본 연구에서는 4 개의 격벽을 일정한 간격으로 배치하였다. 탱크 제원과 적재량에 따 른 탱크 고유주기는 다음 식으로 구할 수 있다.

$$
\omega_{n}=\sqrt{\frac{n \pi g}{L} \tanh \left(\frac{n \pi h}{L}\right)}
$$

여기서 $L$ 은 탱크 길이, $h$ 는 적재량, $n$ 은 운동 모드 수, $g$ 는 중 력가속도이다. 본 연구에서 탱크 내부의 격벽은 탱크 적재량에 영향을 주지 않는 형태로 탱크의 고유주기를 유지하면서 위상 각을 변화시키는 장치로 사용되었다. ART의 제원과 적재량 및 그에 따른 고유주기는 Table 3 에 나타나 있다. 단, 격벽 효과의 확인을 위해 고유주기는 격벽 효과를 고려하지 않고 계산하였 으며 그 값은 Table 3에 나타나있다. 또한 ART의 위치에 의한 영향을 평가하기 위해 $x$ 축 방향으로 3 가지 경우를 설정하였으 며, 그 위치는 선수부, 선체 중앙, 그리고 선미부로 설정하였다. $\mathrm{ART}$ 를 탑재한 선박의 운동 시뮬레이션에 앞서 격벽의 효과를 확인하기 위해 $\mathrm{ART}$ 의 단독 운동 시뮬레이션을 수행하였다. 탱크 는 Table 3에 나타나 있는 탱크를 사용하였으며 격벽이 있는 경 우와 없는 경우에 대해 각각 시뮬레이션을 수행하였다. 탱크는 부유체의 좌우동요 및 횡동요 운동의 영향이 지배적이기 때문에 $y$ 축 상에서 $y=0.5 \sin [(2 \pi) /(1.3 t)]$ 으로 강제 운동한다. ART의 단 독 운동 시률레이션은 적재량이 $50 \%$ 가 넘어 2상유동이 발생할 수 있는 범위를 제외한 $43 \%$ 적재된 경우에 대해 시률레이션을 수행하였다. 탱크의 강제 운동 주기는 고유주기에 인접한 값으로 식 (9)에 의해 $1.3 \mathrm{~s}$ 로 설정하였다. 격벽의 유무에 따른 ART의 고 
Table 3 Characteristics of floating vessel and anti-rolling tank

\begin{tabular}{cc}
\hline \hline Description & ART Tanks (A / B / C) \\
\hline Length [m] & $27 / 27 / 27$ \\
Breadth [m] & $40 / 40 / 40$ \\
Height [m] & $7 / 7 / 7$ \\
x-Position [m] (From the center of vessel) & $130 / 0 /-130$ \\
y-position [m] (From the center of vessel) & $0 / 0$ \\
z-Position [m] (From the center of vessel) & $3 / 3$ \\
Filling ratio & $0 \%, 43 \%(0.422 \mathrm{rad} / \mathrm{s}), 57 \%(0.484 \mathrm{rad} / \mathrm{s}), 73 \%(0.536 \mathrm{rad} / \mathrm{s})$ \\
\hline
\end{tabular}

유주기의 변화를 확인하기 위해 $\mathrm{ART}$ 의 벽면에 가해는 압력을 측 정하였으며, 측정 방식은 3 차원 $\mathrm{ART}$ 의 좌측면의 바닥으로부터 $1.2 \mathrm{~m}$ 위에 위치한 지점에서의 값을 평균화 하였다. 이는 전체 벽 면의 압력을 측정하였을 시 설정한 바닥면으로부터 $1.2 \mathrm{~m}$ 떨어진 지점에서의 압력값이 지배적이었기 때문에 그 이외의 압력을 모 두 계산하게 되면 노이즈 등에 의해 정확한 값의 측정이 어렵다
고 판단하였다. 측정 부위에서의 압력비교와(Fig. 3(a))와 압력의 Fast Fourier transfer 방식을 이용한 주파수영역 변환값 비교(Fig. $3(\mathrm{~b}))$ 를 통해 탱크 내 유체 적재률(43\%)에 따른 고유주기는 약 $0.5 \mathrm{rad} / \mathrm{s}$ 로 일치함을 알 수 있다. 그러나 격벽 효과에 의해 고유주 기에서 압력은 감소하고 약 $0.25 \mathrm{rad} / \mathrm{s}$ 와 $0.75 \mathrm{rad} / \mathrm{s}$ 에서 압력이 증 가하는 것을 알 수 있다. 이는 격벽이 탱크 내부 유동에 의해 발

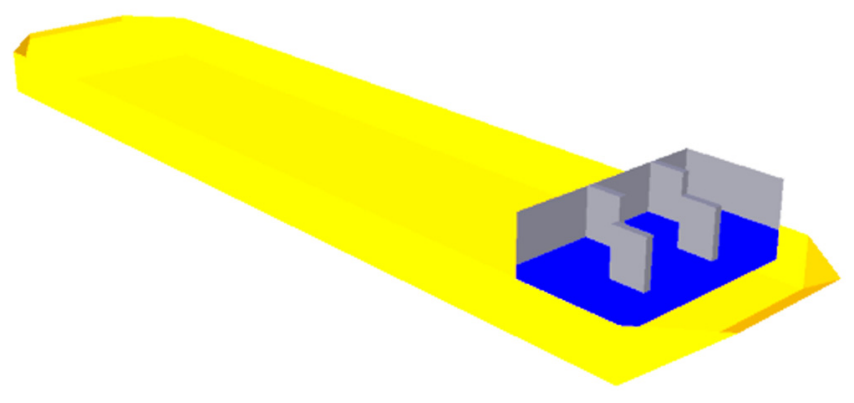

(a)

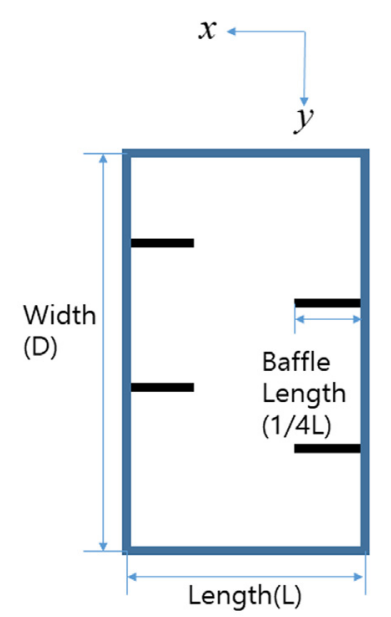

(b)

Fig. 2 Schematic models of (a) floating vessel and (b) anti-rolling tank

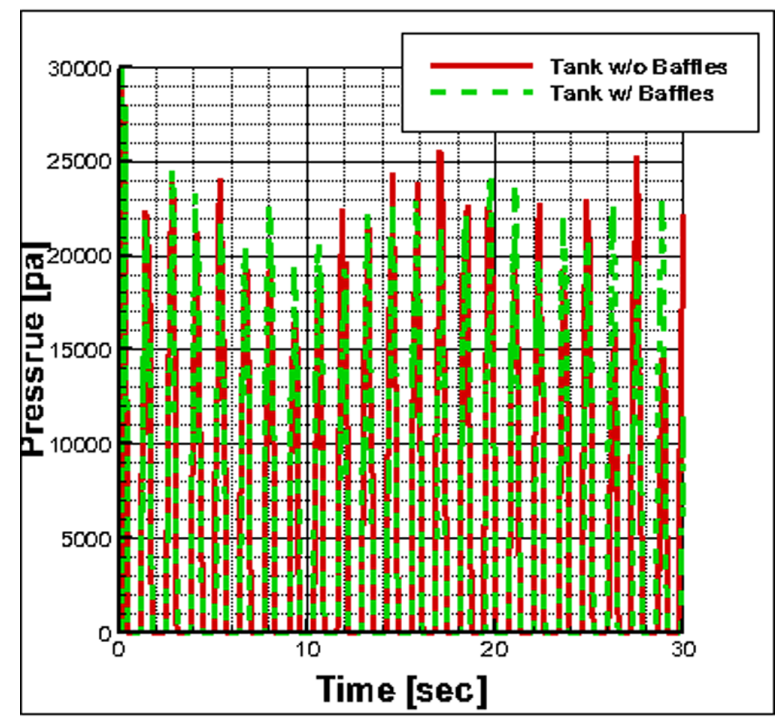

(a)

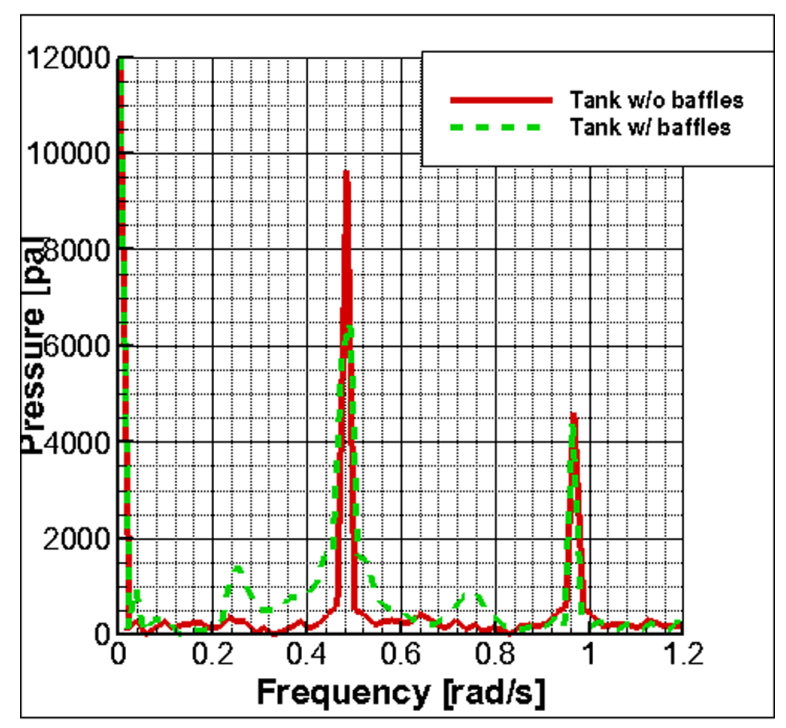

(b)

Fig. 3 Comparison of baffles effects from (a) time history and (b) FFT results 
생하는 하중의 위상 변화를 줄 수 있음을 알 수 있다. 또한 Cho et al.(2017)을 통해 PNU-MPS법을 이용한 격벽의 효과 및 검증 결과를 재확인할 수 있다. PNU-MPS법을 이용한 이유는 ART를 이용한 문제는 단상 유동이며, 이미 많은 연구를 통해 확립된 안 정적인 방법론을 선택하기 위함이다.

ART가 부유체 운동에 미치는 영향을 평가하기 위해 환경조 건은 MARIN에서 수행한 실험과 동일하며, Table 2에 나타나 있 다. 부유체의 운동은 $\mathrm{ART}$ 의 성능에 직접적인 영향을 미칠 것으 로 판단되는 좌우동요와 횡동요만을 고려하였다. 시뮬레이션에 사용된 유체 입자는 적재율이 $43 \%$ 인 경우 69,056 개, $57 \%$ 인 경 우 77,592 개, $71 \%$ 인 경우 86,128 개이며, 초기 입자간 거리는 모 두 $0.5 \mathrm{~m}$ 이다. 중력가속도는 $9.81 \mathrm{~m} / \mathrm{s}^{2}$, 동점성계수는 $10^{-6} \mathrm{~m}^{2} / \mathrm{s}$ 이며 표면장력 효과는 무시하였다. 또한 격벽의 두께는 입자 4 개의 두께로써 $2 \mathrm{~m}$ 의 두께를 가지도록 설정하였다.

Fig. 4는 ART의 적재율에 따른 선박의 좌우동요 및 횡동요에 대한 진폭 응답 함수(RAO, Response amplitude operators)이다. 좌우동요에 대해서는 의미 있는 변화가 없음이 관찰되었다. 이 는 ART가 좌우동요에는 영향을 끼치지 않음을 알 수 있다. 횡 동요 운동에 대해서는 Fig. 1의 시뮬레이션 결과와는 다른 경향 을 보인다. Fig 4에서는 내부 유동에 의해 진폭 응답 함수의 진 폭과 극점의 주기의 변화가 관찰된 반면, $\mathrm{ART}$ 의 경우에는 극점 주기는 변하지 않고 진폭만 변하였다. 이는 ART가 횡동요 운동
을 억제만 하고 부유체의 고유 특성은 변화시키지 않는다는 것 을 알 수 있다. 따라서 ART는 횡동요 운동 저감 본연의 목적에 효과적임을 알 수 있다.

$\mathrm{ART}$ 의 위치가 부유체 운동에 미치는 영향을 확인하기 위해 Table 3에서 나타난 것과 같이 선수, 선체중앙, 선미에 $\mathrm{ART}$ 를 배치하고 시뮬레이션을 수행하였다. Fig. 5 는 표 2의 환경조건 하에서 적재율이 $43 \%$ 일 때 ART를 탑재한 부유체의 운동에 대 한 진폭 응답 함수이다. 만약 ART의 적재율이 동일하다면 ART 의 위치에 따른 진폭 응답 함수의 유의미한 변화가 없음이 관 찰할 수 있었다. 이는 횡동요 운동에 영향을 미치는 주요인자는 $\mathrm{ART}$ 의 위치가 아니라 ART의 존재여부와 적재율임을 알 수 있 다. ART의 영향에 대한 계산은 선박의 중심으로부터 탱크까지 의 거리를 이용하였다. 입자법의 경우는 각각의 입자가 물리량 을 가지고 운동하기 때문에 절대좌표계에서의 위치가 주어지면 이를 이용한 질량의 이동 및 자유표면의 운동에 의한 관성모멘 트는 쉽게 구해질 수 있다. 본 연구에서는 외력으로써의 내부 유체의 영향을 운동방정식에 적용하였으며, 운동방정식의 질량 행렬에 대한 무게중심의 이동 및 관성모멘트 변화는 반영하지 않았다. 또한 충전율이 $50 \%$ 가 넘는 경우 내부 유동이 단산유동 이 아닌 2상 유동으로 변화될 수 있으나, 본 연구의 목적에는 그 변화가 큰 비중을 차지하고 있지 않다고 판단하여 단상 유 동으로 가정하였다.

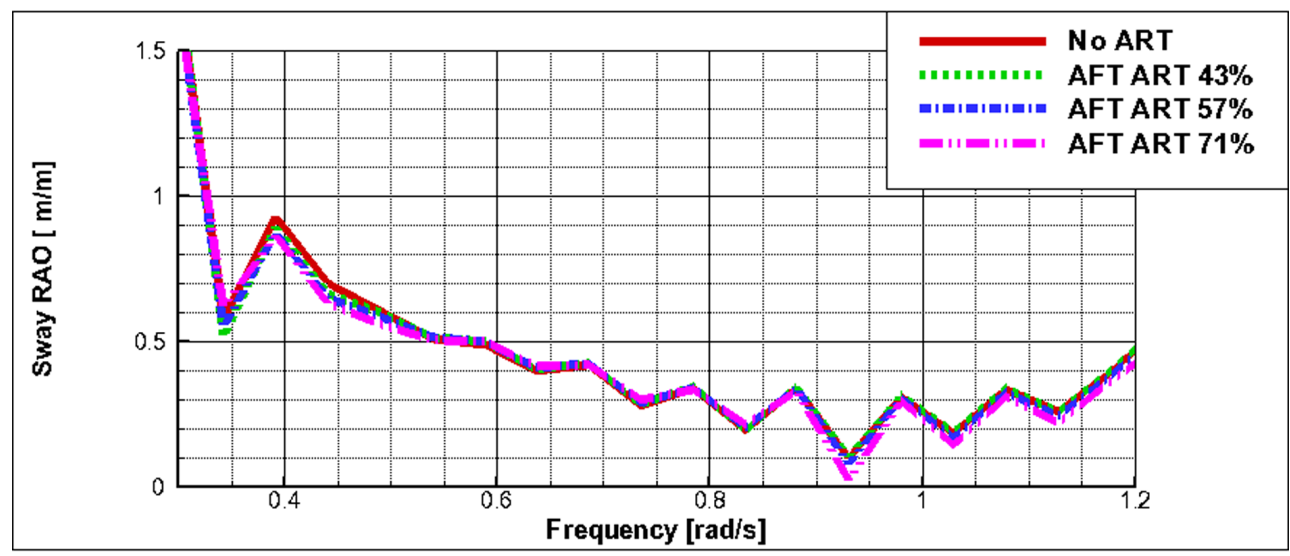

(a)

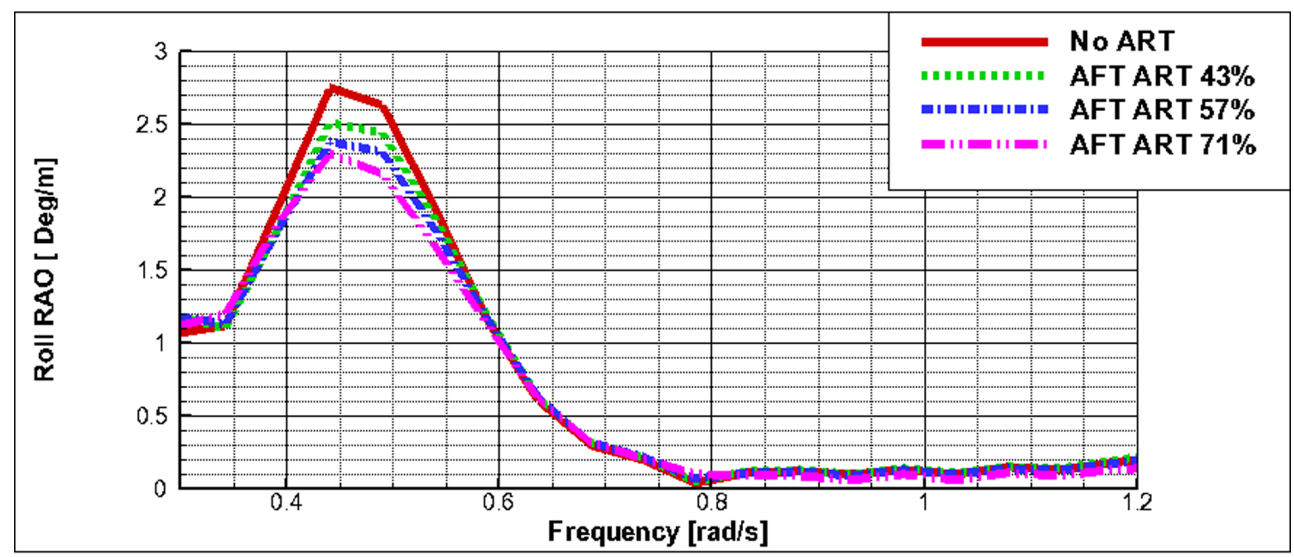

(b)

Fig. 4 RAO of FPSO with variously filled ART for (a) sway motion and (b) roll motion 


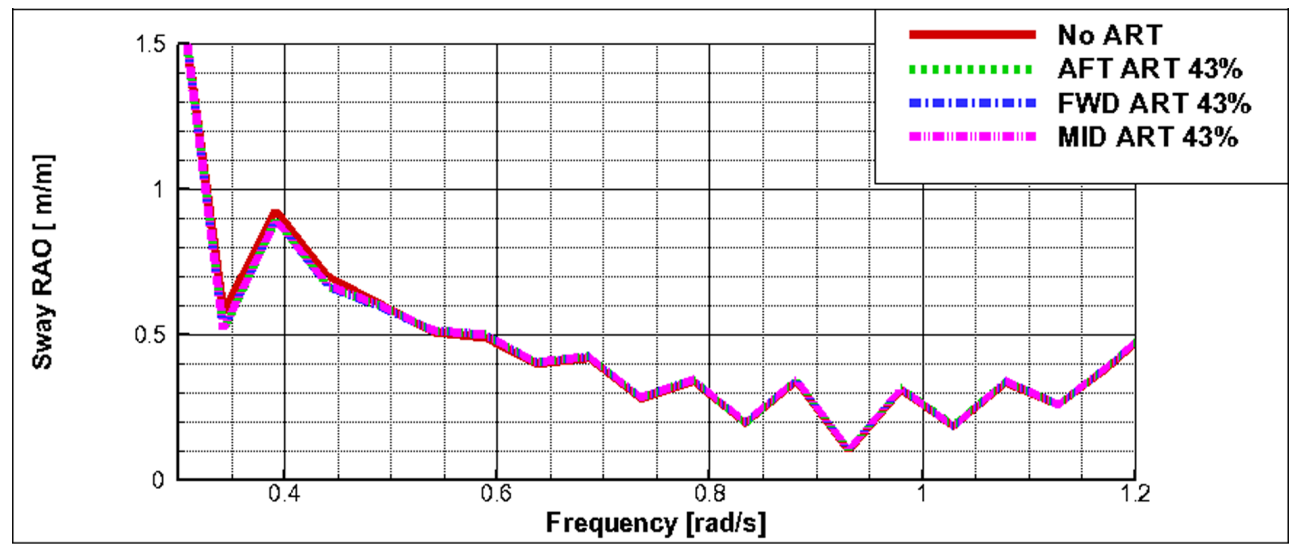

(a)

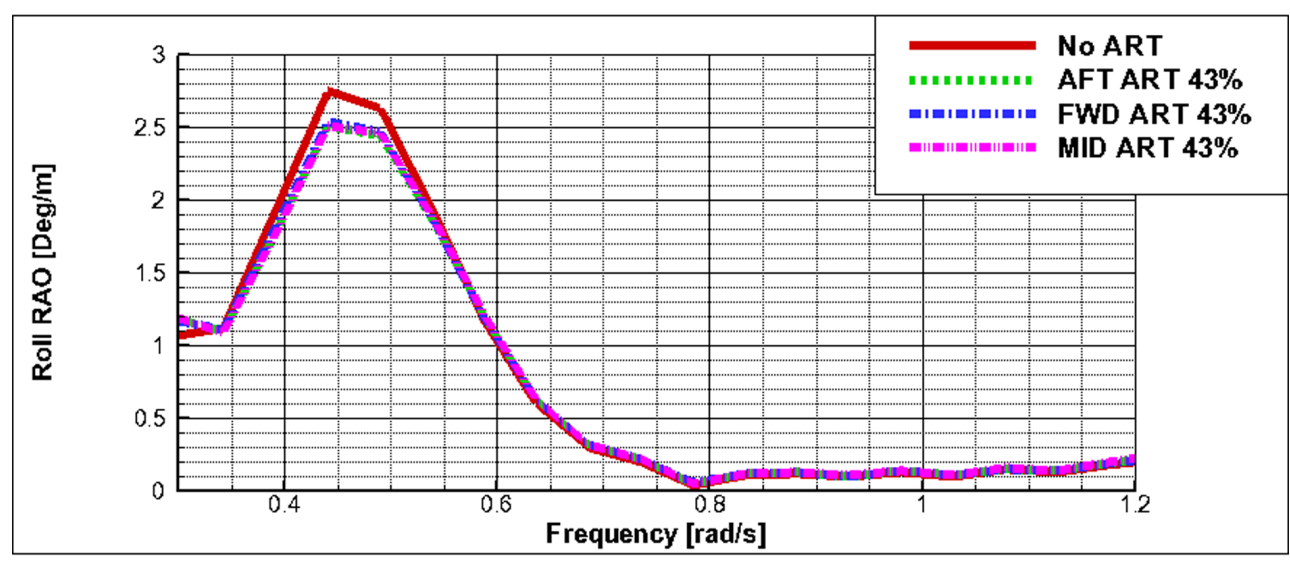

(b)

Fig. 5 RAO of FPSO with variously positioned ART for (a) sway motion and (b) roll motion

\section{4. 결론 및 고찰}

본 연구에서는 부유체 운동 프로그램과 입자기반 전산유체역 학 프로그램을 동적 연성하여 부유체 운동에 ART가 미치는 영 향에 대해 연구를 수행하였다. 선박의 운동은 포텐셜 기반의 $\mathrm{BEM}$ 을 이용하였으며, ART 내부 유동의 시뮬레이션은 MPS법 을 이용하였다.

본 연구에서는 단상 유동형 입자기반 전산유체역학 프로그램 인 PNU-MPS법을 사용하여 격벽이 추가된 내부 유체 탱크 단독 실험을 수행하였다. 측정 된 압력의 시계열을 이용하여 주파수 계열에서의 시계열을 확보하였으며, 확보된 주파수계열의 데이 터를 통해 고유주기의 변화를 관찰하였다. 그 결과 격벽의 유무 에 따라 탱크의 고유주기는 위상의 변화로 인해 변화가 발생함 을 알 수 있었다.

본 연구에서 고안된 ART는 좌우동요에는 영향을 미치지 않 고, 횡동요에 대해 진폭 응답 함수의 값(진폭)을 감소시키면서 도 고유주기의 변화는 없음이 확인되었다. 이는 ART 추가로 인 해 횡동요 운동은 저감되며, 설계 시 고유주기의 변화에 따른 영향을 고려할 필요가 없음을 의미한다.

본 연구는 ART를 이용한 부유체 운동 제어의 기반이 될 것으 로 사료되며, 향후 ART 내 격벽의 크기 및 개수 등이 선박의 운동에 미치는 영향에 대해 연구할 예정이다.

\section{후기}

본 연구는 2018학년도 동명대학교 교내학술연구비지원(과제 번호/2018F027) 및 2018년도 정부(교육부)의 재원으로 한국연구 재단의 지원을 받아 수행된 기초연구사업(No. NRF-2018R1D1A1 $\mathrm{B} 07048254)$ 지원에 의해 이루어졌습니다. 지원에 감사드립니다.

\section{References}

Cho, I.H., Choi, J.S., Kim, M.H., 2017. Sloshing Reduction in a Swaying Rectangular Tank by an Horizontal Porous Baffle. Ocean Engineering, 138, 23-34.

Kim, K.S., Lee, B.H., Kim, M.H., Park, J.C., 2011. Simulation Effect on Vessel Motions by Using MPS(Moving Particle Simulation). Computer Modeling in Engineering and Sciences, 79(3), 201-221.

Kim, K.S., Kim, M.H., Park, J.C., 2014a. Development of Moving Particle Simulation Method for Multiliquid-Layer Sloshing. Mathematical Problems in Engineering, 2014, 350165.

Kim, K.S., Kim, M.H., Park, J.C., 2014b. Dynamic Coupling Between Ship Motion and Three-Layer-Liquid Separator by Using Moving Particle Simulation. International Journal of Offshore 
and Polar Engineering, 24(02), 122-128.

Kim, K.S., Lee, B.H., Kim, M.H., Park, J.C., Choi, H.S., 2016. A Study of Anti-Rolling Tank on Floating Vessel. In ASME 2016 35th International Conference on Ocean, Offshore and Arctic Engineering.

Kim, S.P., Chung, S.M., Shin, W.J., Cho, D.S., Park, J.C., 2018. Experimental Study on Sloshing Reduction Effects of Baffles Linked to a Spring System. Ocean Engineering, 170, 136-147.

Koshizuka, S., Oka, Y., 1996. Moving-particle Semi-implicit Method for Fragmentation of Incompressible Fluid. Nuclear Science and Engineering, 123(3), 421-434.

Lee, B.H., Park, J.C., Kim, M.H., Hwang, S.C., 2011. Step-by-step Improvement of MPS Method in Simulating Violent Free-surface Motions and Impact-loads. Computer Methods in Applied Mechanics and Engineering, 200(9), 1113-1125.

Lee C.H., 1991. Second-order wave loads on a stationary body. 6th International Workshop on Water Waves and Floating Bodies, Woods Hole.

Lee, S.J., Kim, M.H., 2010. The Effects of Inner Liquid Motion on LNG Vessel Responses. Journal of Offshore Mechanics and Arctic Engineering, 132(2), 021101.

Marzouk, O.A., Nayfeh, A.H., 2009. Control of Ship Roll Using Passive and Active Anti-roll Tanks. Ocean Engineering, 36(9-10), 661-671.

Monaghan, J.J., 1994. Simulating Free Surface Flows with SPH. Journal of Computational Physics, 110(2), 399-406.

Nomura, K., Koshizuka, S., Oka, A., Obata, H., 2001. Numerical Analysis of Droplet Breakup Behavior Using Particle Method. Journal of Nuclear Science and Technology, 38(12), 1057-1064.

Tanaka, M., Masunaga, T., 2010. Stabilization and Smoothing of Pressure in MPS Method by Quasi-compressibility. Journal of Computational Physics, 229(11), 4279-4290.

Xu, R., Stansby, P., Laurence, D., 2009. Accuracy and Stability in Incompressible SPH (ISPH) Based on the Projection Method and a New Approach. Journal of Computational Physics, 228(18), 6703-6725.

Yang, C.K., Kim, M.H., 2011. The Structural Safety Assessment of a Tie-down System on a Tension Leg Platform During Hurricane Events, Ocean Syst Eng, 1(4), 263-293. 